\title{
Topical bromfenac for prevention and treatment of cystoid macular edema following cataract surgery: a review
}

This article was published in the following Dove Press journal:

Clinical Ophthalmology

25 October 2016

Number of times this article has been viewed

\author{
John D Sheppard ${ }^{1,2}$ \\ 'Virginia Eye Consultants, \\ ${ }^{2}$ Department of Ophthalmology, \\ Eastern Virginia Medical School, \\ Norfolk, VA, US
}

Correspondence: John D Sheppard Department of Ophthalmology, Eastern Virginia Medical School, 700 West Olney Road, Norfolk, VA 23507, US

Tel + I 757226802 I

Fax + I 7576242270

Email jsheppard@vec2020.com
Abstract: Topical nonsteroidal anti-inflammatory drugs (NSAIDs) and corticosteroids, alone or in combination, have historically been used off label in the US to prevent and treat postoperative cystoid macular edema (CME). This literature review presents available data on the use of bromfenac $0.07 \%$ or $0.09 \%$ to prevent and treat CME following cataract surgery. Bromfenac is an NSAID approved to treat postoperative inflammation and reduce ocular pain following cataract surgery. Few cases of clinical CME were observed with bromfenac use in a total of 19 reviewed studies. There were no significant differences in CME incidence between bromfenac and corticosteroid-treated patients or between bromfenac- and bromfenac plus corticosteroid-treated patients. Bromfenac demonstrated comparable efficacy to other NSAIDs in preventing CME. Compared with corticosteroids, bromfenac alone or plus a corticosteroid showed similar or better efficacy in minimizing changes in retinal thickness and macular volume. In diabetic cataract surgery patients, bromfenac was comparable or superior to corticosteroids for minimizing changes in retinal thickness; also, combination therapy with bromfenac and corticosteroids may be associated with smaller changes in foveal thickness, macular thickness, and macular volume versus monotherapy with either treatment alone in this patient population. In two randomized, double-masked, placebo-controlled clinical trials with bromfenac $0.07 \%$, CME was reported as an adverse event in $0.5 \%$ and $1.5 \%$ of patients receiving bromfenac and placebo, respectively. In an analysis of four placebo-controlled trials with bromfenac $0.09 \%$, macular edema was reported in $0.7 \%$ and $1.4 \%$ of patients receiving bromfenac and placebo, respectively. When evaluated as treatment for acute or chronic CME, bromfenac was associated with improvement in visual acuity and reduction in retinal thickness, but few studies are available. Overall, published data suggest that bromfenac is safe and effective when used to prevent or treat CME. Large-scale placebo-controlled trials and greater standardization of CME measures are needed to establish optimal bromfenac regimens for the prophylaxis and treatment of CME following cataract surgery.

Keywords: anti-inflammatory agents, nonsteroidal, NSAID, bromfenac, cystoid macular edema, Irvine-Gass syndrome

\section{Introduction}

Cystoid macular edema (CME) following cataract surgery (Irvine-Gass syndrome) was originally described by Irvine ${ }^{1}$ in 1953 and demonstrated angiographically in 1966 by Gass and Norton. ${ }^{2}$ This condition involves accumulation of excess fluid within the macula due to leakage from dilated peri-foveal capillaries. ${ }^{3,4}$ Cystoid spaces consisting of clear fluid are often detectable in the macula and appear to represent areas of the retina in which cells have been displaced. ${ }^{4}$ As one of the most common complications 
of otherwise uncomplicated cataract surgery, ${ }^{5-7} \mathrm{CME}$ remains a leading cause of unexpected vision loss following cataract surgery, ${ }^{7,8}$ even while improvements in surgical techniques such as phacoemulsification and small-incision surgery have lessened the overall risk..$^{9,10}$

Following cataract surgery, CME typically develops within 3 months postoperatively, peaking in incidence between 4 and 6 weeks. ${ }^{8,11,12}$ The reported incidence rates of CME following phacoemulsification vary widely depending on how CME is diagnosed and defined and on the patient population studied. Clinical CME, which involves evidence of macular edema associated with a loss of visual acuity (VA), has been reported at rates ranging from $0 \%$ to $4 \%{ }^{10,11,13-18}$ Fluorescein angiography and optical coherence tomography (OCT) can be used to confirm a diagnosis of clinical CME and/or detect sub-clinical CME. ${ }^{8,9} \mathrm{~A}$ diagnosis of angiographic CME signifies detectable leakage from perifoveal capillaries on fluorescein angiography without a notable loss in VA. ${ }^{9}$ Between $9 \%$ and $30 \%$ of patients develop angiographic CME following phacoemulsification..$^{10,11,19}$ The advantages of OCT are that it is noninvasive, less costly, and more sensitive than fluorescein angiography for detecting $\mathrm{CME}$ and provides an objective and quantifiable measurement of macular thickness that can be useful in standardizing definitions of CME and in monitoring disease activity. ${ }^{8,11,20}$ The reported rates of postoperative CME diagnosed using OCT range from $11 \%$ to $41 \% .{ }^{8,10,20,21}$

The rates of clinical and subclinical CME following uncomplicated cataract surgery are higher in populations with an elevated risk of CME, including patients with diabetes/diabetic retinopathy, previous/recent uveitis, and hypertension and those with a history of retinal vein occlusion. ${ }^{10,13,16,22-25} \mathrm{CME}$ usually responds well to medical therapy or may resolve spontaneously but carries a risk of permanent impairment of central VA or loss of contrast sensitivity. ${ }^{10,16}$ Clinical CME that persists for $>6$ months is considered chronic and has been reported to occur in $9.4 \%-12.8 \%$ of CME cases with postcataract surgery. ${ }^{12,13}$

The pathology of postoperative CME involves a mechanical trauma-triggered cascade of inflammatory events, leading to the synthesis of prostaglandins and other inflammatory mediators primarily or exclusively in the anterior segment. ${ }^{3,9,26}$ Inflammatory mediators stimulate the breakdown of the blood-retinal barrier, resulting in the accumulation of intraretinal fluid and leading to macular thickening and edema. Prostaglandins within the eye also cause vasodilation and leukocyte migration. ${ }^{27}$ Topically applied nonsteroidal anti-inflammatory drugs (NSAIDs) penetrate the ocular tissues and limit prostaglandin synthesis by inhibiting the enzymes cyclooxygenase-1 (COX-1) and cyclooxygenase-2 (COX-2). ${ }^{27-30}$ The inhibition of prostaglandins by COX inhibitors, such as NSAIDs, likely mediates their antiinflammatory and analgesic effects. ${ }^{27-30}$ By inhibiting COX enzymes, NSAIDs prevent the conversion of arachidonic acid to prostacyclins, thromboxanes, and prostaglandins..$^{27,31}$ Because COX-2 has been identified as a key mediator of ocular inflammation, ${ }^{32}$ the ability of NSAIDs to inhibit COX-2 may be especially important with regard to antiinflammatory activity.

A number of meta-analyses and systematic reviews have reported prophylactic anti-inflammatory therapy, including treatment with topical NSAIDs, to be effective in reducing the incidence of CME after cataract surgery. $7,33,34$ A meta-analysis of 16 randomized controlled trials involving 2,898 eyes concluded that prophylaxis with NSAIDs and/ or steroids significantly reduced the risk of angiographic and clinical CME after cataract surgery. ${ }^{33}$ Furthermore, topical NSAIDs, either as monotherapy or combined with topical corticosteroids, appear to be more effective than topical corticosteroids alone for preventing CME. In a systematic review and meta-analysis of the effects of prophylactic anti-inflammatory medication, topical NSAIDs were found to better reduce the risk of developing CME within 3 months after surgery compared to topical corticosteroids in patients without diabetes and in mixed (diabetic/nondiabetic) populations. ${ }^{7}$ Compared to topical corticosteroids alone, combination therapy with topical NSAIDs and corticosteroids significantly reduced the risk of developing CME in patients with and without diabetes. Similarly, a systematic review and meta-analysis of randomized, controlled trials comparing topical NSAIDs with topical steroids in preventing CME following phacoemulsification concluded that the prevalence of CME within 1 month after surgery was significantly lower among patients treated with NSAIDs (3.8\%) compared with those treated with corticosteroids (25.3\%). ${ }^{34}$ Both potent and weaker corticosteroids were less effective than NSAIDs in reducing the risk of CME. In addition, a large retrospective cohort study found that adding an NSAID to postoperative topical prednisolone acetate was associated with a lower risk of clinical CME compared with prednisolone therapy alone (odds ratio $0.45 ; 95 \%$ confidence interval 0.21-0.95). ${ }^{24}$ Clinical CME was defined as evidence of macular thickening on OCT and VA of 20/40 or worse, ascertained between 5 and 120 days after cataract surgery. A recent systematic review of 12 randomized, controlled studies, which specifically evaluated the effectiveness of 
topical NSAIDs at 3 months and beyond for prevention of visual loss postcataract surgery, concluded that there was no level I evidence of such benefit, although the authors acknowledged that there was evidence that topical NSAIDs reduced the risk of CME detected by angiography or OCT and promoted short-term ( $<3$ months) recovery of visual function. ${ }^{35}$ Notably, the American Society of Cataract and Refractive Surgery (ASCRS) did not endorse the conclusions of this analysis, arguing that focusing on VA at 3 months ignored the benefit of NSAIDs in improving visual recovery before that time. The ASCRS further highlighted that a delay in visual rehabilitation could result in patient anxiety, reduced productivity, dependence on others, and costs associated with additional diagnostic testing. ${ }^{36}$

The benefits of topical NSAIDs in treating CME are less well established than their prophylactic effects. A metaanalysis of randomized, controlled studies that examined the effects of NSAIDs (topical fenoprofen, topical ketorolac, topical diclofenac, and oral indomethacin) as treatment of acute (three studies) or chronic (four studies) CME reported that studies in acute CME were underpowered and had inconsistent results, although two of the three studies demonstrated efficacy of topical ketorolac $0.5 \%$, alone or combined with topical corticosteroids. ${ }^{37}$ In studies of NSAIDs as treatment for chronic CME, only topical ketorolac $0.5 \%$ showed a benefit (two of two studies of ketorolac). ${ }^{37}$

The current clinical guidelines on the management of cataract in adults acknowledge evidence suggesting that NSAIDs, either alone or in combination with corticosteroids, are more effective than corticosteroids alone for preventing acute CME. ${ }^{16}$ However, there is no established protocol for prophylaxis of CME in patients undergoing cataract surgery. In addition, consideration of the efficacy of individual topical NSAIDs is of interest since differences between topical NSAIDs in pharmacokinetics and pharmacodynamics may potentially result in different efficacy profiles. Bromfenac is an NSAID that has been used in the treatment of postoperative pain and inflammation since 2000. However, to date, there are no reviews of studies specifically of bromfenac versus other NSAIDS or corticosteroids for CME prophylaxis/treatment. The objective of this review was to summarize available data to date on the use of bromfenac to prevent and treat CME following cataract surgery.

\section{Overview of bromfenac}

Bromfenac sodium is designated chemically as sodium (2-amino-3-[4-bromobenzoyl] phenyl) acetate sesquihydrate. ${ }^{38}$ The addition of a bromine atom to the chemical structure increases the molecule's lipophilicity, enhances penetration into ocular tissues, and increases the potency against COX-1 and COX-2 relative to other NSAIDs. ${ }^{39-42}$ Following a single ocular dose of bromfenac $0.09 \%$ in rabbits, bromfenac was detected within all ocular tissues, with the exception of the vitreous humor, after 24 hours. ${ }^{43}$ However, two studies of patients scheduled to undergo vitrectomy and who did not have vitreous hemorrhage found that bromfenac $0.09 \%$ and other assessed NSAIDs (ketorolac, nepafenac, indomethacin) penetrated into the vitreous cavity. ${ }^{44,45}$ In one of these studies, ${ }^{45}$ but not the other, ${ }^{44}$ bromfenac achieved vitreous levels sufficient to significantly reduce vitreous prostaglandin $\mathrm{E}_{2}\left(\mathrm{PGE}_{2}\right)$ concentrations. A formulation of bromfenac was later developed in which the $\mathrm{pH}$ was lowered (from 8.3 to 7.8 ) to increase the nonionized fraction of the drug and thus facilitate a reduction in dose to $0.07 \%$ while maintaining ocular bioavailability. ${ }^{38} \mathrm{~A}$ recent study in rabbits demonstrated that bromfenac $0.07 \%$ penetrated ocular tissues at similar levels to those observed with bromfenac $0.09 \%{ }^{46}$

Bromfenac inhibits COX-2 in vitro approximately three to four times more potently than other ophthalmic NSAIDs, with a half maximal inhibitory concentration $\left(\mathrm{IC}_{50}\right)$ of $0.0066-0.0075 \mu \mathrm{mol} / \mathrm{L}$ compared with amfenac $(0.0204 \mu \mathrm{mol} / \mathrm{L})$, ketorolac $(0.0279-0.12 \mu \mathrm{mol} / \mathrm{L})$, and diclofenac $(0.0307 \mu \mathrm{mol} / \mathrm{L}){ }^{42,47,48}$ however, Walters et $\mathrm{al}^{49}$ observed more potent COX-2 inhibition with amfenac $\left(\mathrm{IC}_{50}, 0.00177 \mu \mathrm{g} / \mathrm{mL}\right)$ compared with bromfenac ( $\mathrm{IC}_{50}$, $0.0112 \mu \mathrm{g} / \mathrm{mL}$ ) and ketorolac $\left(\mathrm{IC}_{50}, 0.0911 \mu \mathrm{g} / \mathrm{mL}\right)$ in a similar assay. In a randomized study of 121 patients scheduled to undergo cataract surgery, inhibition of $\mathrm{PGE}_{2}$ levels in the aqueous humor with bromfenac $0.09 \%$ (instilled BID the day before surgery and once on the day of surgery) was comparable to that observed with nepafenac $0.1 \%$ (given TID on the day before surgery and once on the day of surgery) and ketorolac $0.45 \%$ (given BID on the day before surgery and once on the day of surgery). ${ }^{50}$

\section{Bromfenac approval history}

Bromfenac ophthalmic solution $0.1 \%$ was initially approved in Japan in 2000 (Bronuck $^{\circledR}$; Senju Pharmaceutical Co., Ltd., Osaka, Japan). The same twice-daily formulation was approved in 2005 in the US as bromfenac ophthalmic solution $0.09 \%$ (Xibrom $^{\circledR}$; ISTA Pharmaceuticals Inc., Irvine, CA, USA) for the treatment of postoperative inflammation following cataract extraction. The Japanese formulation is labeled as the salt and thus is equivalent in dose to bromfenac ophthalmic solution 0.09\%. Approval in the US was expanded in 2006 to include the reduction in ocular pain 
after cataract extraction, but the product was discontinued in 2011. In 2010, a once-daily formulation of bromfenac $0.09 \%$ (Bromday $^{\circledR}$; ISTA Pharmaceuticals Inc.) became the first once-daily ophthalmic NSAID in the US approved to treat postoperative inflammation and pain in patients who have undergone cataract extraction with posterior chamber intraocular lens (IOL) implantation. ${ }^{51}$ The current formulation of once-daily bromfenac $0.07 \%$ ophthalmic solution (Prolensa $^{\circledR}$; Bausch \& Lomb Incorporated, Bridgewater, NJ, US) was approved by the US Food and Drug Administration (FDA) in April 2013 for the treatment of postoperative inflammation and reduction of ocular pain following cataract surgery. ${ }^{38}$ Most recently, a polymer-based formulation of bromfenac 0.075\% (BromSite ${ }^{\mathrm{TM}}$; Sun Pharmaceutical Industries Inc., Cranbury, NJ, US) was approved by the FDA for the treatment of postoperative inflammation and prevention of ocular pain following cataract surgery with BID administration. ${ }^{52}$ However, to date, there have been no published studies on this formulation. As with other topical NSAIDs, bromfenac is not FDA indicated for the prevention or treatment of CME.

\section{Treatment of pain and inflammation with bromfenac after cataract surgery}

In placebo-controlled trials, significantly greater proportions of patients treated with either bromfenac $0.07 \%$ (QD) or $0.09 \%$ (QD or BID) achieved complete clearance of ocular inflammation by postsurgical day 15 and were free of ocular pain at postsurgical day 1 compared with placebo-treated patients. ${ }^{53-56}$ In two prospective, randomized, open-label trials, bromfenac $0.1 \%$ showed similar effects compared to betamethasone and combination therapy (bromfenac/ betamethasone) on measures of aqueous flare and corneal thickness following cataract surgery ${ }^{57}$ but cleared ocular inflammation (based on mean photon count) after cataract surgery more rapidly than dexamethasone $0.1 \%(P=0.001)$ and demonstrated a nonsignificant trend toward faster resolution compared to fluorometholone $0.1 \% .{ }^{58}$ A prospective, randomized study found that bromfenac $0.09 \%$ BID, ketorolac $0.4 \%$ TID, and nepafenac $0.1 \%$ TID all reduced postoperative inflammation by laser flare photometry values following phacoemulsification, with nepafenac showing a significantly greater reduction compared with bromfenac, ketorolac, and a no-NSAID control at 4 weeks postsurgery $(P=0.032) .{ }^{59}$ These findings highlight the effectiveness of bromfenac ophthalmic solution given BID or QD for treating ocular inflammation and pain following cataract surgery.

\section{CME data search strategy}

The medical literature was searched for relevant articles using Medline (1990-August 2016) and Embase (1993-August 2016). The search terms included "bromfenac" combined with "cystoid macular edema" and also paired with "cataract surgery". All references citing original clinical data on the use of bromfenac to treat or prevent CME were included. Bibliographies of reviews and other articles were also scanned for additional source material pertinent to the topic. These searches identified 19 relevant published articles or meeting abstracts on the bromfenac $0.07 \%$ and $0.09 \%$ formulations, which are reviewed in the following sections and summarized in Tables 1 and 2.

\section{Bromfenac for the prevention of CME postcataract surgery Studies with CME as a predefined outcome measure}

\section{Bromfenac versus topical corticosteroids}

Six prospective studies and one retrospective analysis compared bromfenac with topical corticosteroids for the prevention of CME following cataract surgery in patients without diabetes or in mixed populations (ie, with or without diabetes). ${ }^{55-58,60-71}$ In a prospective, investigator-masked, randomized study, Duong et al ${ }^{60}$ compared bromfenac $0.09 \%$ with prednisolone acetate $1 \%$ in patients undergoing phacoemulsification. There was no evidence of subclinical (postoperative macular changes by OCT falling outside of 2 standard deviation [SD] of the baseline OCT value) or clinical CME in either treatment group. In both groups, VA improved on postoperative day 1 , improved further at the 1 -month visit, and remained stable at 2 months.

Wang et $\mathrm{al}^{58}$ compared bromfenac $0.1 \%$, fluorometholone $0.1 \%$, and dexamethasone $0.1 \%$ for postsurgical prophylaxis of CME in patients undergoing phacoemulsification in a prospective, randomized, open-label study. Patients with diabetes or uveitis, among other conditions, were excluded from study participation. CME (central retinal thickness $[\mathrm{CRT}]>250 \mu \mathrm{m}$ and the presence of intraretinal cystoid space under the fovea) was not evident with either bromfenac regimen over 2 months of follow-up, while there were three cases in the fluorometholone group $(7 \%$ of 43 patients) and four cases in the dexamethasone group ( $9.8 \%$ of 41 patients). The overall between-group difference was statistically significant $(P=0.038)$; however, post hoc comparisons between individual treatment regimens were not significant. Mean \pm SD postoperative retinal foveal thickness at 2 months was significantly lower in the bromfenac 


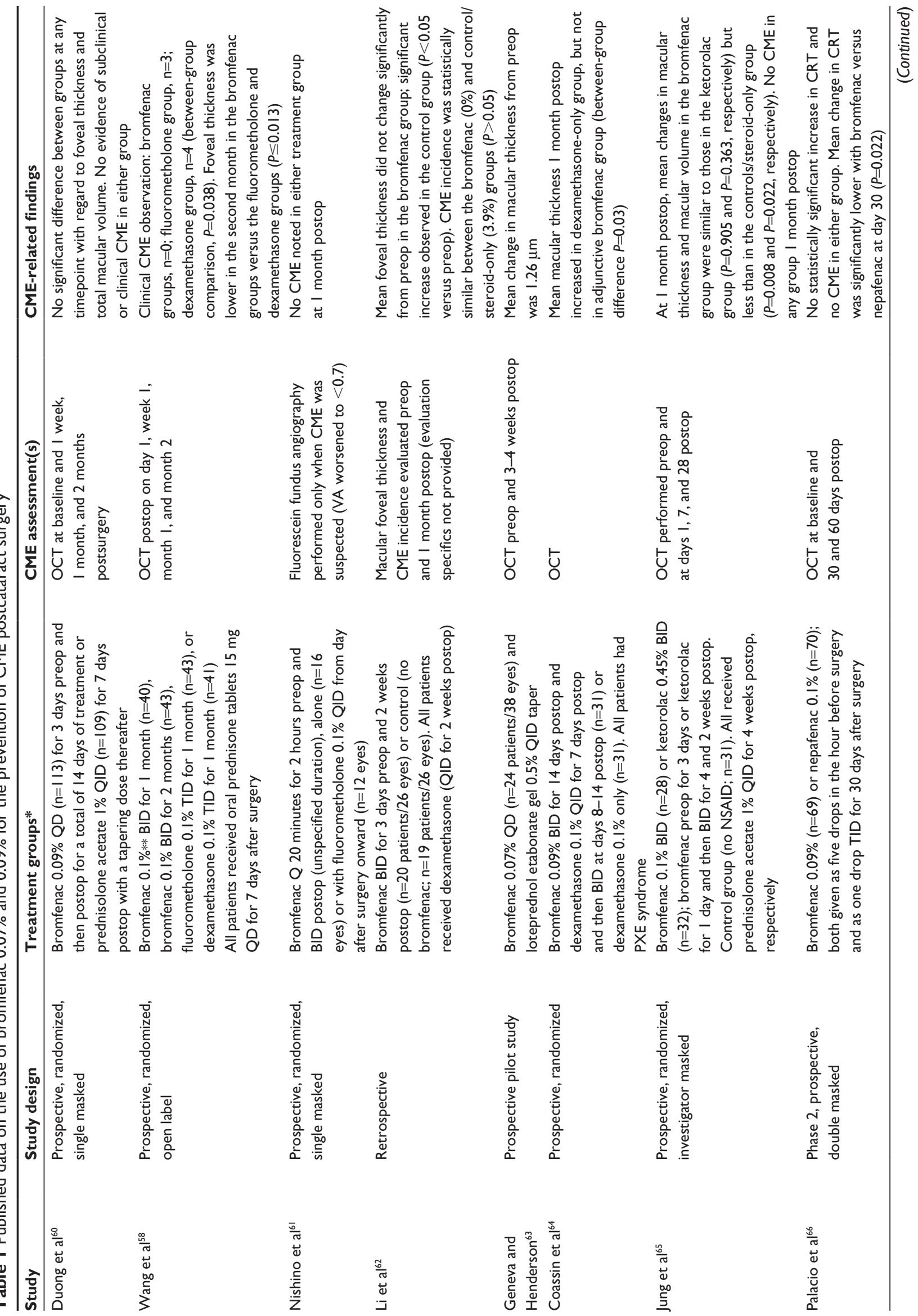




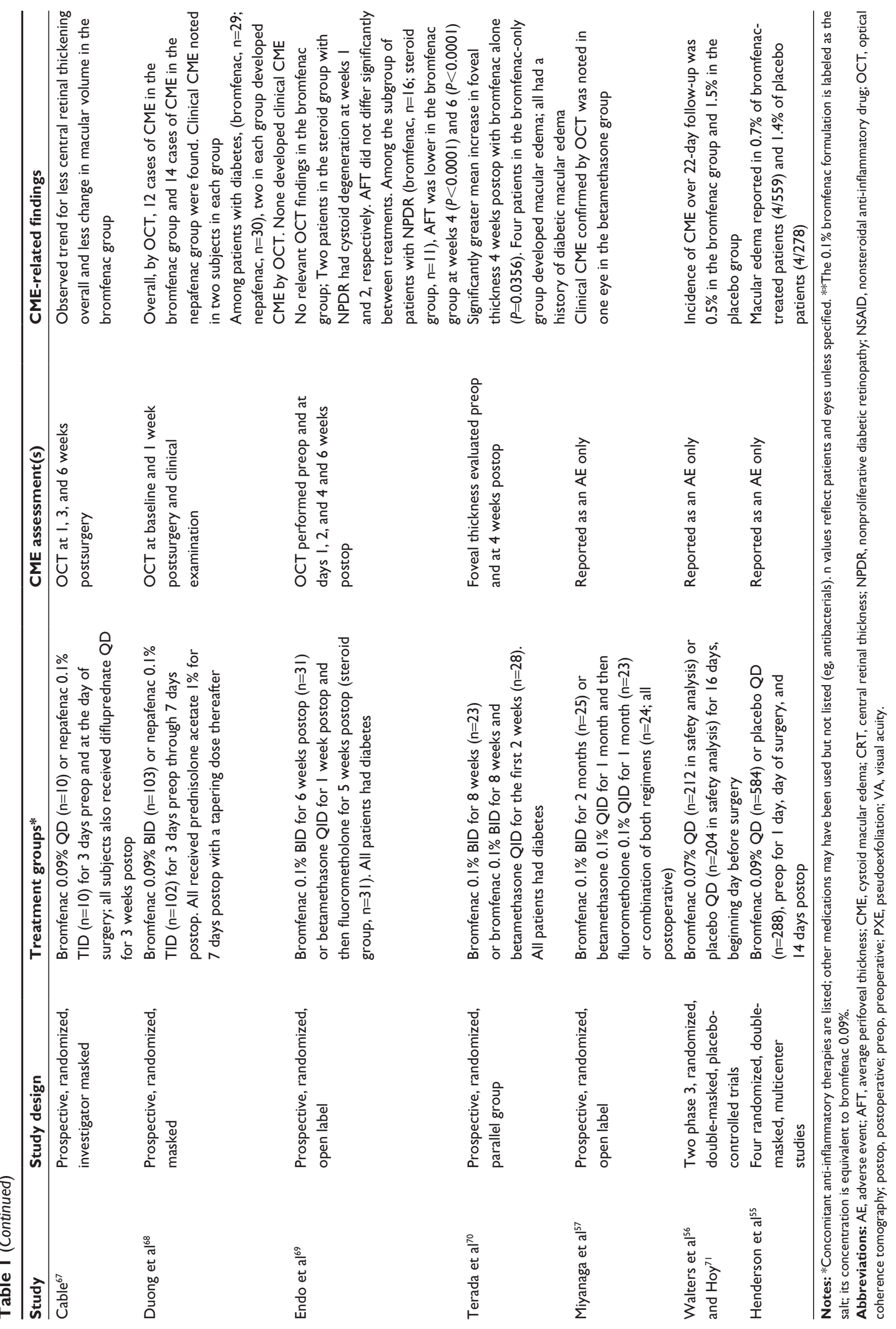


Table 2 Published data on the use of bromfenac $0.09 \%$ for the treatment of CME

\begin{tabular}{|c|c|c|c|}
\hline Study & $\begin{array}{l}\text { Study } \\
\text { design }\end{array}$ & Treatment groups & Findings \\
\hline Rho et $\mathrm{al}^{75}$ & Prospective & $\begin{array}{l}\text { Patients exhibiting CME within I year after } \\
\text { uncomplicated cataract surgery, treated with one } \\
\text { of the following drugs for } 3 \text { months: } \\
\text { - bromfenac } 0.09 \% \text { BID }(n=62) \\
\text { - diclofenac } 0.1 \% \text { QID }(n=52) \\
\text { - ketorolac } 0.5 \% \text { QID }(n=52)\end{array}$ & $\begin{array}{l}\text { All treatments resulted in an improvement in VA } \\
\text { with a significant difference in favor of bromfenac } \\
\text { compared to ketorolac }(P=0.036)\end{array}$ \\
\hline Saviano et $\mathrm{al}^{76}$ & Case report & $\begin{array}{l}\text { 69-year-old white woman with CME I6 days } \\
\text { after uncomplicated phacoemulsification cataract } \\
\text { surgery. Standard postop regimen (tobramycin/ } \\
\text { dexamethasone/diclofenac) was discontinued } \\
\text { on day } 16 \text {, and bromfenac } 0.9 \mathrm{mg} / \mathrm{mL} \text { BID was } \\
\text { initiated }\end{array}$ & $\begin{array}{l}\text { Five days after bromfenac was initiated, the OCT } \\
\text { showed a reduction in central foveal retinal thickness } \\
\text { (from } 857 \text { to } 205 \mu \mathrm{m} \text { ) and optically empty intraretinal } \\
\text { spaces. Treatment was continued for another I } 4 \text { days. } \\
\text { At follow-up } ~ I \text { month after bromfenac was initiated, } \\
\text { CME was resolved; retinal thickness was } 203 \mu \mathrm{m} \text { and } \\
\text { the corrected distance VA was } 0.00 \text { logMAR }\end{array}$ \\
\hline Warren et $\mathrm{al}^{77}$ & $\begin{array}{l}\text { Prospective, } \\
\text { randomized, } \\
\text { investigator } \\
\text { masked }\end{array}$ & $\begin{array}{l}39 \text { patients with chronic pseudophakic CME } \\
\text { randomized to treatment with one of the following } \\
\text { drugs for } 16 \text { weeks: } \\
\text { - diclofenac } 0.1 \% \text { TID }(n=7) \\
\text { - ketorolac } 0.4 \% \text { TID }(n=8) \\
\text { - nepafenac } 0.1 \% \text { TID }(n=8) \\
\text { - bromfenac } 0.09 \% \text { BID }(n=8) \\
\text { - placebo BID ( } n=8) \\
\text { All patients also received intravitreal triamcinolone } \\
\text { (at study entry) and bevacizumab injections (at study } \\
\text { entry and at I month) }\end{array}$ & $\begin{array}{l}\text { Compared with placebo, bromfenac and nepafenac } \\
\text { produced significantly greater reductions in retinal } \\
\text { thickness at I } 2 \text { and } 16 \text { weeks. VA improvement at } \\
\text { week } 16 \text { was significant only in the nepafenac-treated } \\
\text { group }\end{array}$ \\
\hline Kadrmas $^{78}$ & Retrospective & $\begin{array}{l}\text { I I cases of CME unresponsive to ketorolac } 0.4 \% \text { QID } \\
\text { treatment following cataract surgery subsequently } \\
\text { switched to treatment with bromfenac } 0.09 \% \text { BID; } \\
\text { length of bromfenac treatment averaged } 20.1 \text { weeks } \\
\text { (range I0-40 weeks) compared to previous treatment } \\
\text { with ketorolac of } 23 \text { weeks (range } 9-50 \text { weeks) }\end{array}$ & $\begin{array}{l}\text { All II eyes showed complete resolution of CME } \\
\text { after treatment with bromfenac as well as an average } \\
\text { visual improvement of I } 2.7 \text { Snellen letters (SEM } 3.8 \\
\text { letters). The mean (SEM) decrease in central macular } \\
\text { thickness and central macular volume was } 58.3 \mu \mathrm{m} \\
(I 7.6 \mu \mathrm{m}) \text { and } 0.18 \mathrm{~mm}^{3}\left(0.05 \mathrm{~mm}^{3}\right) \text {, respectively }\end{array}$ \\
\hline
\end{tabular}

Abbreviations: CME, cystoid macular edema; OCT, optical coherence tomography; SEM, standard error of the mean; postop, postoperative; VA, visual acuity.

1 month group $(208.51 \pm 32.20 \mu \mathrm{m})$ and in the bromfenac 2 months group $(210.45 \pm 26.04 \mu \mathrm{m})$ compared with the fluorometholone $(239.49 \pm 44.94 \mu \mathrm{m})$ and dexamethasone $(241.29 \pm 53.60 \mu \mathrm{m})$ groups $(P<0.02$ for all between-group comparisons). However, there were no significant differences between treatment groups in VA at 2 months.

Nishino et $\mathrm{al}^{61}$ conducted a small prospective, investigatormasked, randomized study evaluating postsurgical use of bromfenac alone or bromfenac plus fluorometholone $0.1 \%$. Patients with poorly controlled diabetes, uveitis, and other conditions associated with possible risk of blood-aqueous barrier breakdown were excluded. No cases of clinical CME occurred in either treatment group. At 1 month after surgery, best-corrected visual acuity (BCVA) improved in $76 \%$ of eyes in the steroid group and $75 \%$ of eyes in the nonsteroid group and was unchanged in the remaining subjects in each group.

Li et $\mathrm{a}^{62}$ retrospectively analyzed data from patients undergoing phacoemulsification who were treated with topical bromfenac combined with dexamethasone or dexamethasone alone. The incidence of $\mathrm{CME}$ was $0 \%$ with bromfenac plus dexamethasone versus 3.9\% with dexamethasone only $(P>0.05)$. In addition, the postoperative mean foveal thickness was significantly higher at 1 month after surgery among patients treated with dexamethasone only $(249.538 \pm 63.153 \mu \mathrm{m})$ compared with those who also received bromfenac $(222.769 \pm 21.562 \mu \mathrm{m}, P<0.05)$.

A prospective, open-label pilot study by Geneva and Henderson $^{63}$ evaluated the effectiveness of postoperative bromfenac $0.07 \%$ combined with loteprednol etabonate gel $0.5 \%$ for preventing macular thickening following phacoemulsification. The mean change in macular thickness at 3 to 4 weeks after surgery was small $(1.26 \mu \mathrm{m}$, range -11 to $+5 \mu \mathrm{m}$ ), suggesting that the combination of bromfenac $0.07 \%$ with a topical corticosteroid regimen may effectively minimize macular thickening following cataract surgery.

A prospective, randomized clinical study of cataract patients with pseudoexfoliation syndrome by Coassin et $\mathrm{al}^{64}$ showed that the addition of bromfenac $0.09 \%$ to topical 
dexamethasone $0.1 \%$ was associated with greater reduction in inflammation than steroid alone. At 4 weeks postsurgery, patients receiving both the steroid and bromfenac showed less mean \pm SD macular thickening by OCT $(243.38 \pm 28.23$ versus $261 \pm 34.50, P=0.03)$ and fewer intra-retinal cysts by OCT ( $0 \%$ versus $14 \%, P<0.05)$.

Finally, Jung et a ${ }^{65}$ reported on the results of a prospective, investigator-masked randomized clinical trial comparing bromfenac $0.1 \%$ and ketorolac $0.45 \%$ beginning 3 days (bromfenac) or 1 day (ketorolac) prior to surgery and continuing for 4 weeks and 2 weeks, respectively, postsurgery. A control group received no NSAID. All patients received prednisolone acetate $1 \%$ for 4 weeks postoperatively. No patient in any treatment group exhibited CME, defined as the presence of cystoid changes associated with $\geq 40 \mu \mathrm{m}$ retinal thickening, at 1 month after surgery. Compared with steroid alone, patients treated with bromfenac and steroid demonstrated significantly smaller changes in mean $\pm \mathrm{SD}$ central foveal subfield (CFS) thickness (4.30 \pm 4.25 versus $12.47 \pm 12.24 \mu \mathrm{m}, P=0.010)$, macular thickness $(6.58 \pm 6.23$ versus $12.03 \pm 7.79 \mu \mathrm{m}, P=0.008)$, and macular volume $\left(0.13 \pm 0.17\right.$ versus $\left.0.26 \pm 0.19 \mathrm{~mm}^{3}, P=0.022\right)$ at 1 month postsurgery. No adverse events (AEs) were reported in the bromfenac or control group; there was one case of mild burning sensation in the ketorolac group.

\section{Bromfenac versus other NSAIDs}

Bromfenac was compared with other NSAIDs for the prevention of postoperative $\mathrm{CME}$ in four prospective studies that enrolled patients without diabetes or in mixed populations. In the study by Jung et $\mathrm{al}^{65}$ comparing bromfenac $0.1 \%$ and ketorolac $0.45 \%$ in patients also receiving prednisolone acetate (described earlier), there were no cases of postcataract surgery CME at 1 month follow-up. No statistically significant differences between bromfenac and ketorolac treatment groups were observed with regard to changes in CFS thickness, macular thickness, or macular volume at 1 month postsurgery.

A phase 2, multicenter, double-masked clinical trial reported by Palacio et al ${ }^{66}$ compared bromfenac $0.09 \%$ with nepafenac $0.1 \%$ in patients undergoing phacoemulsification. No patient in either treatment group developed CME, defined as CRT $\geq 275 \mu \mathrm{m}$ over 60 days. There was no change in CRT relative to baseline for either group at days 30 and 60; however, CRT was significantly lower with bromfenac versus nepafenac at postsurgical day $30(P=0.022)$. There were no AEs considered related to either treatment.

Cable $^{67}$ conducted a prospective, investigator-masked, randomized trial comparing preoperative use of bromfenac
$0.09 \%$ or nepafenac $0.1 \%$ in patients undergoing cataract extraction with posterior chamber IOL implantation. The study drugs were administered for 3 days before and on the day of surgery. All patients received prednisolone acetate $1 \%$ during surgery and difluprednate QD for 3 weeks after surgery. Small increases in macular volume over the postoperative period were observed for each group. However, the increase in macular volume from baseline to week 6 was statistically significant in the nepafenac group $(P=0.006)$ but not in the bromfenac group. Stable or improved VA was attained by $90 \%$ of bromfenac-treated patients and $80 \%$ of those in the nepafenac group over 6 weeks. Compared with nepafenac, bromfenac was associated with significant improvement in BCVA at week $6(P=0.040)$.

Duong et $\mathrm{al}^{68}$ prospectively compared bromfenac $0.09 \%$ and nepafenac $0.1 \%$ in a randomized, masked study in patients undergoing cataract surgery. Both treatments were administered for 3 days prior to surgery and continued through 7 days postsurgery. All patients additionally received prednisolone acetate $1 \%$ for 7 days postsurgery with a tapering dose thereafter. There was no difference between treatment groups in the incidence of CME detected by OCT ( $n=14$ bromfenac, $n=13$ nepafenac) or clinical CME $(n=3$ in both groups) over 1 month after surgery. There were also no significant differences between the treatment groups with regard to changes in VA at 1 month and foveal or central foveal thickness at 1 week after surgery, as well as intraocular pressure (IOP) at the follow-up visits.

\section{Findings in postcataract patients with diabetes}

The findings on the efficacy of bromfenac for the prevention of CME in cataract surgery patients with diabetes are derived from two studies conducted specifically in this patient population ${ }^{69,70}$ and from three subanalyses of data from studies that included patients with diabetes..$^{60,65,68}$

One of the previously described studies by Duong et al ${ }^{60}$ comparing bromfenac $0.09 \%$ and prednisolone acetate $1 \%$ included 44 cataract surgery patients with diabetes (22 in each treatment group). In this subgroup with diabetes, there were no significant differences between treatments at 1 week, 1 month, and 2 months postsurgery with regard to anterior segment inflammation, foveal thickness, or total macular volume.

In a prospective, randomized, open-label study, Endo et $\mathrm{a}^{69}$ compared the efficacy of bromfenac $0.1 \%$ and steroid therapy in preventing CME after cataract surgery with IOL implantation in patients with diabetes. Nonproliferative diabetic retinopathy (NPDR) was present in 16 eyes $(51.6 \%)$ in the bromfenac group and 11 eyes $(35.5 \%)$ in the steroid group. 
The patients received bromfenac $0.1 \%$ postoperatively for 6 weeks or betamethasone and fradiomycin for 1 week after surgery followed by fluorometholone $0.1 \%$ for 5 weeks. Cystoid degeneration was not seen in the bromfenac group, but was noted in two patients with NPDR in the steroid group. There was no significant difference between groups in average perifoveal thickness (AFT) or BCVA, the latter of which improved postoperatively in both groups over 6 weeks. Anterior chamber flare decreased to the preoperative level by 2 weeks in the bromfenac group but remained elevated through week 6 in the steroid group; at 2 weeks, the difference between treatment groups was statistically significant $(P=0.007)$. A subanalysis of patients with NPDR found that AFT did not differ between the bromfenac and steroid groups preoperatively but was significantly lower in the bromfenac group at weeks $4(211.1 \pm 19.4$ versus $276.6 \pm 86.8 \mu \mathrm{m}, P<0.0001)$ and $6(214.5 \pm 18.0$ versus $272.5 \pm 86.3 \mu \mathrm{m}, P<0.0001)$.

In a prospective study by Terada et al, ${ }^{70}$ patients with diabetes undergoing cataract surgery were randomly assigned to postsurgical treatment with bromfenac $0.1 \%$ monotherapy for 8 weeks or combined therapy with bromfenac $0.1 \%$ for 8 weeks along with betamethasone $0.1 \%$ for the first 2 weeks. The mean \pm SD increase in foveal thickness 4 weeks postoperatively was significantly greater in patients receiving bromfenac monotherapy compared with those receiving bromfenac plus betamethasone treatment $(25.26 \pm 35.78$ versus $6.35 \pm 8.02 \mu \mathrm{m}, P=0.036)$. Four patients in the bromfenac monotherapy group (17.4\%), all of whom had a history of diabetic macular edema, developed macular edema after surgery, whereas no cases of postsurgical macular edema were reported in the combined therapy group. There were no differences between treatment groups with regard to changes in anterior chamber flare, BCVA (up to 8 weeks postsurgery), corneal thickness, or IOP.

In the study of Jung et al, ${ }^{65}$ described earlier, seven patients $(25 \%)$ in the bromfenac group, nine $(28.1 \%)$ in the ketorolac group, and eight (25.8\%) in the control group had diabetes. Changes in CSF thickness, macular thickness, and macular volume at 1 month after surgery were significantly greater among patients with diabetes than among those without diabetes receiving postoperative prednisolone acetate $1 \%$ but not among patients additionally receiving preoperative and postoperative bromfenac $0.1 \%$ or ketorolac $0.45 \%$.

A subanalysis of patients with diabetes from the study of Duong et al ${ }^{68}$ compared 29 eyes treated with bromfenac $0.09 \%$ and 30 eyes treated with nepafenac $0.1 \%$, both in combination with postoperative prednisolone acetate. None of the patients with diabetes in either treatment group developed clinical $\mathrm{CME}$, and two patients in each group developed CME by OCT within 1 month postsurgery. No differences between treatment groups in foveal thickness or central foveal thickness at 1 week postsurgery were observed.

\section{Studies reporting CME as an $\mathrm{AE}$}

A randomized, open-label trial by Miyanaga et $\mathrm{al}^{57}$ assessed inflammatory reactions following phacoemulsification in patients treated postsurgically with one of three regimens: bromfenac $0.1 \%$ alone, betamethasone $0.1 \%$ followed by fluorometholone $0.1 \%$, or a combination of both regimens. Patients with various comorbidities, including diabetes and uveitis among others, were excluded. While CME was not a predefined study outcome, one case of clinical CME, confirmed with OCT, was identified 1 month after surgery in a subject using betamethasone; no cases of $\mathrm{CME}$ were reported in the other two treatment groups. In all treatment groups, VA improved rapidly over the first week postsurgery, and improvements were sustained over 2 months.

Two publications were identified in which CME outcomes were reported as safety findings in placebo-controlled studies of the efficacy of bromfenac in the treatment of postcataract surgery inflammation and pain..$^{55,56,71}$ In an integrated analysis of data from two phase 3, placebo-controlled trials, the incidence of CME was $0.5 \%$ among patients treated with bromfenac $0.07 \%$ and $1.5 \%$ among placebo-treated patients. $^{56,71}$

A pooled analysis of data from four multicenter, randomized, double-masked clinical trials in the US found that the incidence of macular edema reported as an AE (assessed by clinical observation, OCT, or fluorescein angiography) over the duration of treatment (15 or 16 days) and follow-up (7 days) was $0.7 \%$ in the bromfenac $0.09 \%$ group versus $1.4 \%$ in the placebo group. ${ }^{55}$ Compared with the placebo group, the bromfenac group demonstrated significantly greater improvement in VA at 3, 8, 15, and 22 days postsurgery $(P \leq 0.02)$, providing a viable but imperfect surrogate for CME. ${ }^{14,23,72,73}$

\section{Discussion regarding bromfenac for CME prevention}

In addition to prevention of pain and inflammation following cataract surgery, bromfenac is accepted by many ophthalmologists as a first-line drug for the prevention of postcataract CME. Review of the available literature suggests that bromfenac, either alone or in conjunction with a corticosteroid, is effective for preventing CME following cataract surgery. No significant differences in the incidence of CME were observed when bromfenac monotherapy was 
compared to steroid monotherapy ${ }^{57,60}$ or bromfenac used in conjunction with a steroid. ${ }^{61}$ Studies comparing bromfenac with other NSAIDs observed no significant differences in the CME rates between bromfenac and nepafenac when given alone or in combination with corticosteroids ${ }^{66,68}$ or between bromfenac and ketorolac when given in combination with a corticosteroid. ${ }^{65}$

Increases in CRT or other markers of macular changes that do not meet criteria for clinically significant CME may signal a tendency toward CME or may potentially be associated with subtle visual disturbances. ${ }^{74}$ Studies suggest that changes in such markers may be lower with bromfenac compared with corticosteroid therapy ${ }^{58}$ and lower when combined with a corticosteroid compared with corticosteroid monotherapy. ${ }^{65}$ Compared with other NSAIDs, bromfenac is associated with similar or smaller changes in CRT and macular volume ${ }^{66,67}$ Thus, bromfenac should be considered for the off-label prevention of CME following cataract surgery. It proves superior or equivalent in most published clinical trials when compared to other commercially available topical NSAID preparations.

Analysis of the effects of NSAIDS, including bromfenac, for the prevention of CME following cataract surgery is limited by the absence of placebo-controlled trials designed specifically to investigate this indication. In addition, most trials were small, with differences in study design and definitions of CME, and several studies excluded patients with diabetes and uveitis or other risk factors for CME. ${ }^{57,58,61}$

Data from studies of bromfenac use in postcataract surgery patients with diabetes suggest that corticosteroid therapy alone may be insufficient to reduce macular thickness and volume and that the addition of an NSAID may be necessary in this at-risk patient population in order to achieve optimal reductions in CRT. ${ }^{65,70}$ Additional studies are indicated to further explore the potential benefits of combination therapy compared with NSAID or corticosteroid monotherapy in diabetics and to identify optimal treatment regimens. Clinical data also suggest that another group of high-risk patients with pseudoexfoliation syndrome ${ }^{64}$ may benefit from topical steroid synergy with bromfenac.

\section{Bromfenac for the treatment of CME}

\section{Treatment of acute CME}

In addition to being evaluated for the prevention of CME following cataract surgery, bromfenac has been investigated as a treatment of acute and chronic CME postsurgery. A prospective study compared bromfenac $0.09 \%$, diclofenac $0.1 \%$, and ketorolac $0.5 \%$ in 166 patients with acute CME, which developed within 1 year of uncomplicated cataract surgery. ${ }^{75}$ After 3 months, the mean letters gained were significantly greater among patients treated with bromfenac compared with ketorolac ( $17.3 \pm 10.5$ versus $14.0 \pm 6.2, P=0.036)$, while there was no significant difference between bromfenac and diclofenac.

Saviano et $\mathrm{al}^{76}$ described in a case report the successful treatment of CME that developed in a 69 -year-old patient initially managed postoperatively with dexamethasone $0.1 \%$ TID for 7 days and diclofenac BID or TID for 14 days. At 16 days after surgery, the patient presented with reduced VA, reduced color perception, and metamorphopsia; OCT confirmed CME, with a foveal thickness of $857 \mu \mathrm{m}$, and showed optically empty intraretinal spaces. Diclofenac therapy was discontinued, and treatment was initiated with topical bromfenac $0.9 \%$ BID. Five days after starting bromfenac therapy, VA had improved, and the patient reported improvement in color perception and metamorphopsia. At 23 days, central retinal foveal thickness was normal $(203 \mu \mathrm{m})$, the optically empty intraretinal spaces had disappeared, VA was normal, and the patient reported complete resolution of visual symptoms.

\section{Treatment of chronic CME}

A single-center, randomized, investigator-masked, 16-week study compared four topical NSAIDs (bromfenac 0.09\% BID, diclofenac $0.1 \%$ TID, ketorolac $0.4 \%$ TID, and nepafenac $0.1 \%$ TID) with placebo in 39 patients with chronic pseudophakic CME (mean duration, 9.4 months). ${ }^{77}$ All patients additionally received intravitreal triamcinolone $4 \mathrm{mg}$ at study entry. Patients with conditions associated with a risk of macular edema (eg, diabetes, uveitis, posterior capsular compromise) were excluded. The mean retinal thickness at 12 and 16 weeks was significantly different among treatment groups $(P=0.0001)$, due to greater reductions in the bromfenac and nepafenac groups. At 16 weeks, percent reductions in mean retinal thickness were significantly greater compared with placebo (14\%) for bromfenac $(36 \%, P=0.0113)$ and nepafenac ( $49 \%, P=0.0048)$, but not for diclofenac and ketorolac. VA improved significantly only in the nepafenac group. Modest and transient increases in IOP were observed in patients receiving intravitreal therapy plus placebo, and a similar pattern occurred in the NSAID treatment groups; two patients each in the placebo and nepafenac groups and one patient each in the bromfenac, diclofenac, and ketorolac groups developed increased IOP. Three patients (two in the nepafenac group who experienced foreign body sensation 
and one in the ketorolac group who developed conjunctival injection) discontinued the study because of AEs.

The efficacy of bromfenac for treating chronic CME following cataract surgery was assessed in a retrospective analysis of 11 cases of CME unresponsive to treatment with ketorolac $0.4 \%$ QID (average length of treatment 23 weeks; range 9-50 weeks). ${ }^{78}$ Bromfenac $0.09 \%$ BID monotherapy was continued for an average of 20.1 weeks (range 10-40 weeks). All 11 eyes showed complete clinical resolution of CME (average visual improvement \pm standard error of the mean [SEM], 12.7 \pm 3.8 Snellen letters) and macular edema by OCT, with average \pm SEM decreases in central macular thickness and central macular volume of $58.3 \pm 17.6 \mu \mathrm{m}$ and $0.18 \pm 0.05 \mathrm{~mm}^{3}$, respectively. The results of this small study suggest the potential of bromfenac to treat CME in patients who do not respond to ketorolac.

\section{Discussion regarding bromfenac for CME treatment}

Bromfenac is accepted by many ophthalmologists as a firstline drug for the treatment of acute and chronic CME postcataract surgery, as well as for the treatment of at-risk uveitic or diabetic patients where the literature support is lacking. In summary, the results of two prospective studies indicate that bromfenac is similar or superior to other NSAIDs with regard to improvement in VA at 3 months in patients with acute $\mathrm{CME}^{75}$ and reduction in retinal thickness at 16 weeks in patients with chronic $\mathrm{CME} .{ }^{77}$ Less rigorous data (ie, case study, retrospective analysis) suggest that bromfenac treatment may achieve resolution of clinical CME in patients who did not respond to another NSAID. ${ }^{76,78}$

\section{Conclusion}

There is currently no established protocol for CME prevention. Optimal pharmacologic management of CME following cataract surgery continues to be debated. The American Academy of Ophthalmology Preferred Practice Pattern on cataract cites evidence that NSAIDs alone or in combination with corticosteroids are more effective than corticosteroids alone in treating postcataract CME. ${ }^{16}$ Overall, published data with bromfenac $0.07 \%$ and $0.09 \%$ strongly suggest the efficacy for the prevention of CME or markers of macular changes and for the treatment of CME. Few studies of bromfenac for the prevention or treatment of CME directly reported safety outcomes, although the studies that did so found bromfenac to be safe and well tolerated, with minimal risk of increased IOP. ${ }^{57,58,61,65,66,68,69,77}$ In the placebo-controlled studies cited in this review, ${ }^{55,56}$ the incidence of AEs was significantly lower in bromfenac-treated groups compared with placebo groups.

There remains a need for well-designed studies in this therapeutic area to establish optimal treatment regimens for bromfenac and other therapies for the prophylaxis and treatment of CME following cataract surgery. Future initiatives should consider the standardization of CME definitions and the inclusion of clinically relevant measures of visual function beyond Snellen VA, including OCT, contrast sensitivity, and quality-of-life metrics. With the societal burden of cataract surgery burgeoning, cost-effective preventive therapeutic recommendations for routine and at-risk patients can best be formulated using evidence-based medicine derived from sound prospective trial design, adequate cohort size, and valid statistical analysis.

\section{Acknowledgment}

Writing and editing assistance was provided by Churchill Communications (Maplewood, NJ, USA) and funded by Bausch \& Lomb, Inc.

\section{Disclosure}

Dr Sheppard is an advisory board member, speakers bureau participant, and clinical research investigator for Bausch \& Lomb, Inc., and also reports receiving consulting fees from Bausch \& Lomb, Inc.

\section{References}

1. Irvine SR. A newly defined vitreous syndrome following cataract surgery; interpreted according to recent concepts of the structure of the vitreous; the Seventh Francis I. Proctor Lecture. Am J Ophthalmol. 1953; 36(5):599-619.

2. Gass JD, Norton EW. Cystoid macular edema and papilledema following cataract extraction: a fluorescein fundoscopic and angiographic study. Arch Ophthalmol. 1966;76(5):646-661.

3. Flach AJ. The incidence, pathogenesis and treatment of cystoid macular edema following cataract surgery. Trans Am Ophthalmol Soc. 1998; 96:557-634.

4. Rotsos TG, Moschos MM. Cystoid macular edema. Clin Ophthalmol. 2008;2(4):919-930.

5. Zaida FH, Corbett MC, Burton BJ, Bloom PA. Raising the benchmark for the 21 st century - the 1000 cataract operations audit and survey: outcomes, consultant-supervised training and sourcing NHS choice. BrJ Ophthalmol. 2007;91(6):731-736.

6. Greenberg PB, Tseng VL, Wu WC, et al. Prevalence and predictors of ocular complications associated with cataract surgery in United States veterans. Ophthalmology. 2011;118(3):507-514.

7. Wielders LHP, Lambermont VA, Schouten JSAG, et al. Prevention of cystoid macular edema after cataract surgery in nondiabetic and diabetic patients: a systematic review and meta-analysis. Am J Ophthalmol. 2015;160(5):968-981.

8. Yonekawa Y, Kim IK. Pseudophakic cystoid macular edema. Curr Opin Ophthalmol. 2012;23(1):26-32.

9. Lobo C. Pseudophakic cystoid macular edema. Ophthalmologica. 2012;227(2):61-67. 
10. Guo S, Patel S, Baumrind K, et al. Management of pseudophakic cystoid macular edema. Surv Ophthalmol. 2015;60(2):123-137.

11. Kim SJ, Bressler NM. Optical coherence tomography and cataract surgery. Curr Opin Ophthalmol. 2009;20(1):46-51.

12. Daien V, Papinaud L, Domerg C, Lacombe S, Daures JP, Villain M. Incidence and characteristics of cystoid macular edema after cataract surgery. Ophthalmology. 2016;123(3):663-664.

13. Henderson BA, Kim JY, Ament CS, Ferrufino-Ponce ZK, Grabowska A, Cremers SL. Clinical pseudophakic cystoid macular edema: risk factors for development and duration after treatment. J Cataract Refract Surg. 2007;33:1550-1558.

14. Cagini C, Fiore T, Iaccheri B, Piccinelli F, Ricci MA, Fruttini D. Macular thickness measured by optical coherence tomography in a healthy population before and after uncomplicated cataract phacoemulsification surgery. Curr Eye Res. 2009;34(12):1036-1041.

15. Jaycock P, Johnston RL, Taylor H, et al. The Cataract National Dataset electronic multi-centre audit of 55,567 operations: updating benchmark standards of care in the United Kingdom and internationally. Eye (Lond). 2009;23(1):38-49.

16. American Academy of Ophthalmology Cataract and Anterior Segment Panel [homepage on the Internet]. Preferred Practice Pattern ${ }^{\circledR}$ Guidelines. Cataract in the Adult Eye. San Francisco, CA: American Academy of Ophthalmology; 2011. Available from: www.aao.org/ppp. Accessed March 2, 2016.

17. Packer M, Lowe J, Fine H. Incidence of acute postoperative cystoid macular edema in clinical practice. $J$ Cataract Refract Surg. 2012;38(12): $2108-2111$.

18. Chaudhary C, Bahadhur H, Gupta N. Study of cystoid macular edema by optical coherent tomography following uneventful cataract surgery. Int Ophthalmol. 2015;35(5):685-691.

19. Mentes J, Erakgun T, Afrashi F, Kerci G. Incidence of cystoid macular edema after uncomplicated phacoemulsification. Ophthalmologica. 2003;217(6):408-412.

20. Kim SJ, Equi R, Bressler NM. Analysis of macular edema after cataract surgery in patients with diabetes using optical coherence tomography. Ophthalmology. 2007;114(5):881-889.

21. Lobo CL, Faria PM, Soares MA, Bernardes RC, Cunha-Vaz JG. Macular alterations after small-incision cataract surgery. $J$ Cataract Refract Surg. 2004;30(4):752-760.

22. Eriksson U, Alm A, Bjärnhall G, Granstam E, Matsson AW. Macular edema and visual outcome following cataract surgery in patients with diabetic retinopathy and controls. Graefes Arch Clin Exp Ophthalmol. 2011;249(3):349-359.

23. Katsimpris JM, Petropoulos IK, Zoukas G, Patokos T, Brinkmann CK, Theoulakis PE. Central foveal thickness before and after cataract surgery in normal and in diabetic patients without retinopathy. Klin Monbl Augenheilkd. 2012;229(4):331-337.

24. Shorstein NH, Liu L, Waxman MD, Herrinton LJ. Comparative effectiveness of three prophylactic strategies to prevent clinical macular edema after phacoemulsification surgery. Ophthalmology. 2015;122(12): 2450-2456.

25. Chu CJ, Johnston RL, Buscombe C, Sallam AB, Mohamed Q, Yang YC; United Kingdom Pseudophakic Macular Edema Study Group. Risk factors and incidence of macular edema after cataract surgery: a database study of 81,984 eyes. Ophthalmology. 2016;123: 316-323.

26. Miyake K, Ibaraki N. Prostaglandins and cystoid macular edema. Surv Ophthalmol. 2002;47(suppl 1):S203-S218.

27. Kim SJ, Flach AJ, Jampol LM. Nonsteroidal anti-inflammatory drugs in ophthalmology. Surv Ophthalmol. 2010;55(2):108-133.

28. Flach AJ. Topical nonsteroidal antiinflammatory drugs in ophthalmology. Int Ophthalmol Clin. 2002;42(1):1-11.

29. Lindstrom R. The pharmacologic and pathophysiologic rationale for using NSAIDs in ocular inflammatory disease and ocular surgery. Int Ophthalmol Clin. 2006;46(4):7-11.

30. Ahuja M, Dhake AS, Sharma SK, Majumdar DK. Topical ocular delivery of NSAIDs. AAPS J. 2008;10(2):229-241.
31. Farah AE, Rosenberg F. Potential therapeutic applications of aspirin and other cyclo-oxygenase inhibitors. Br J Clin Pharmacol. 1980;10(suppl2): 261S-278S.

32. Oka T, Shearer T, Azuma M. Involvement of cyclooxygenase- 2 in rat models of conjunctivitis. Curr Eye Res. 2004;29(1):27-34.

33. Rossetti L, Chaudhuri J, Dickersin K. Medical prophylaxis and treatment of cystoid macular edema after cataract surgery. The results of a meta-analysis. Ophthalmology. 1998;105(3):397-405.

34. Kessel L, Tendal B, Jorgensen KJ, et al. Post-cataract prevention of inflammation and macular edema by steroid and nonsteroidal antiinflammatory eye drops. A systematic review. Ophthalmology. 2014; 121(10):1915-1924.

35. Kim SJ, Schoenberger SD, Thorne JE, Ehlers JP, Yeh S, Bakri SJ. Topical nonsteroidal anti-inflammatory drugs and cataract surgery. Ophthalmology. 2015;122(11):2159-2168.

36. Jampel HD. Ophthalmic technology assessments. Ophthalmology. 2015;122(11):2157-2158.

37. Sivaprasad S, Bunce C, Crosby-Nwaobi R. Non-steroidal antiinflammatory agents for treating cystoid macular oedema following cataract surgery. Cochrane Database Syst Rev. 2012;2:CD004239.

38. Prolensa [package insert]. Tampa, FL: Bausch and Lomb Inc.; 2013.

39. Walsh DA, Moran HW, Shamblee DA, et al. Antiinflammatory agents. 3. Synthesis and pharmacological evaluation of 2-amino-3-benzoylphenylacetic acid and analogues. J Med Chem. 1984;27(11):1379-1388.

40. Sancilio LF, Nolan JC, Wagner LE, Ward JW. The analgesic and antiinflammatory activity and pharmacologic properties of bromfenac. Arzneimittelforschung. 1987;37(5):513-519.

41. Ruiz J, López M, Milà J, Lozoya E, Lozano JJ, Pouplana R. QSAR and conformational analysis of the anti-inflammatory agent amfenac and analogues. J Comput Aided Mol Des. 1993;7(2):183-198.

42. Kida T, Kozai S, Takahashi H, Isaka M, Tokushige H, Sakamoto T. Pharmacokinetics and efficacy of topically applied nonsteroidal antiinflammatory drugs in retinochoroidal tissues in rabbits. PLoS One. 2014;9:e96481.

43. Baklayan GA, Patterson HM, Song CK, Gow JA, McNamara TR. 24-hour evaluation of the ocular distribution of (14)C-labeled bromfenac following topical instillation into the eyes of New Zealand white rabbits. J Ocul Pharmacol Ther. 2008;24(4):392-398.

44. Heier JS, Awh CC, Busbee BG, et al. Vitreous nonsteroidal antiinflammatory drug concentrations and prostaglandin E2 levels in vitrectomy patients treated with ketorolac $0.4 \%$, bromfenac $0.09 \%$, and nepafenac 0.1\%. Retina. 2009;29(9):1310-1313.

45. Russo A, Morescalchi F, Vezzoli S, et al. Reduction of vitreous prostaglandin E2 levels after topical administration of indomethacin $0.5 \%$, bromfenac $0.09 \%$, and nepafenac $0.1 \%$. Retina. 2016;36(6):1227-1231.

46. Baklayan GA, Muñoz M. The ocular distribution of (14)C-labeled bromfenac ophthalmic solution $0.07 \%$ in a rabbit model. Clin Ophthalmol. 2014;8:1717-1724.

47. Waterbury LD, Silliman D, Jolas T. Comparison of cyclooxygenase inhibitory activity and ocular anti-inflammatory effects of ketorolac tromethamine and bromfenac sodium. Curr Med Res Opin. 2006;22(6): $1133-1140$.

48. Kida T, Ogawa T, Mcnamara TR, et al. Evaluation of the human Cox-2 inhibition of amfenac, bromfenac, diclofenac, and ketorolac. In: Proceedings of the American Society of Cataract and Refractive Surgery (ASCRS), San Diego, CA, April 27-May 2, 2007.

49. Walters T, Raizman M, Ernest P, Gayton J, Lehmann R. In vivo pharmacokinetics and in vitro pharmacodynamics of nepafenac, amfenac, ketorolac, and bromfenac. J Cataract Refract Surg. 2007;33(9): 1539-1545.

50. Bucci FA Jr, Waterbury LD. Prostaglandin E2 inhibition of ketorolac $0.45 \%$, bromfenac $0.09 \%$, and nepafenac $0.1 \%$ in patients undergoing phacoemulsification. Adv Ther. 2011;28(12):1089-1095.

51. Bromday [prescribing information]. Irvine, CA: ISTA Pharmaceuticals, Inc.; 2012.

52. BromSite [prescribing information]. Cranbury NJ, Sun Pharma Industries, Inc.; April 2016. 
53. Donnenfeld ED, Holland EJ, Stewart RH, Gow JA, Grillone LR; Bromfenac Ophthalmic Solution 0.09\% (Xibrom) Study group. Bromfenac ophthalmic solution $0.09 \%$ (Xibrom) for postoperative ocular pain and inflammation. Ophthalmology. 2007;114(9):1653-1662.

54. Silverstein SM, Cable MG, Sadri E, et al. Once daily dosing of bromfenac ophthalmic solution $0.09 \%$ for postoperative ocular inflammation and pain. Curr Med Res Opin. 2011;27(9):1693-1703.

55. Henderson BA, Gayton JL, Chandler SP, et al. Safety and efficacy of bromfenac ophthalmic solution (Bromday) dosed once daily for postoperative ocular inflammation and pain. Ophthalmology. 2011;118(11): 2120-2127.

56. Walters TR, Goldberg DF, Peace JH, Gow JA; Bromfenac Ophthalmic Solution $0.07 \%$ Once Daily Study Group. Bromfenac ophthalmic solution $0.07 \%$ dosed once daily for cataract surgery: results of 2 randomized controlled trials. Ophthalmology. 2014;121(1):25-33.

57. Miyanaga M, Miyai T, Nejima R, Maruyama Y, Miyata K, Kato S. Effect of bromfenac ophthalmic solution on ocular inflammation following cataract surgery. Acta Ophthalmol. 2009;87(3):300-305.

58. Wang QW, Yao $\mathrm{K}, \mathrm{Xu} \mathrm{W}$, et al. Bromfenac sodium $0.1 \%$, fluorometholone 0.15 and dexamethasone $0.1 \%$ for control of ocular inflammation and prevention of cystoid macular edema after phacoemulsification. Ophthalmologica. 2013;229(4):187-194.

59. Sahu S, Ram J, Bansal R, Pandav SS, Gupta A. Effect of topical ketorolac $0.4 \%$, nepafenac $0.1 \%$, and bromfenac $0.009 \%$ on postoperative inflammation using laser flare photometry in patients having phacoemulsification. J Cataract Refract Surg. 2015;41:2043-2048.

60. Duong H-VQ, Westfield KC, Singleton IC. Treatment paradigm after uncomplicated cataract surgery: a prospective evaluation. Asia Pac J Ophthalmol (Phila). 2014;3(4):220-225.

61. Nishino M, Eguchi H, Iwata A, Shiota H, Tanaka M, Tanaka T. Are topical steroids essential after an uneventful cataract surgery? J Med Invest. 2009;56(1-2):11-15.

62. Li N, Wang G-Q, Peng X-J, Wang J, Sui Y-L. Effects of bromfenac sodium eyedrops used in perioperative period on macular fovea thickness after cataract surgery: a primary study. Int Eye Sci. 2015;15(10): 1802-1804.

63. Geneva II, Henderson B. Prospective interventional pilot study using bromfenac $0.07 \%$ after cataract surgery for prevention of macular thickening. Am Soc Cat Refract Surg. 2014. Abstract No. 5785.

64. Coassin M, Iovieno A, Soldani A, et al. Bromfenac ophthalmic solution $0.09 \%$ as an adjunctive therapy to topical steroids after cataract surgery in pseudoexfoliation syndrome. J Cat Refract Surg. 2016;42(8): 1119-1125.

65. Jung JW, Chung BH, Kim EK, Seo KY, Kim TI. The effects of two non-steroidal anti-inflammatory drugs, bromfenac $0.1 \%$ and ketorolac 0.45\%, on cataract surgery. Yonsei Med J. 2015;56(6):1671-1677.
66. Palacio C, Fernández De Ortega L, Bustos FR, Chávez E, OregonMiranda AA, Mercado-Sesma AR. Bromfenac 0.09\% bioavailability in aqueous humor, prophylactic effect on cystoid macular edema, and clinical signs of ocular inflammation after phacoemulsification in a Mexican population. Clin Ophthalmol. 2016;10:233-237.

67. Cable M. Comparison of bromfenac $0.009 \%$ QD to nepafenac $0.1 \%$ TID after cataract surgery: pilot evaluation of visual acuity, macular volume, and retinal thickness at a single site. Clin Ophthalmol. 2012;6: 997-1004

68. Duong HVQ, Westfield KC, Singleton IC. Comparing the efficacy of bromfenac $0.09 \%$ and nepafenac $0.1 \%$ post cataract surgery: a prospective evaluation. J Clin Exp Ophthalmol. 2011;2:8.

69. Endo N, Kato S, Haruyama K, Shoji M, Kitano S. Efficacy of bromfenac sodium ophthalmic solution in preventing cystoid macular oedema after cataract surgery in patient with diabetes. Acta Ophthalmol. 2010;88(8): 896-900.

70. Terada Y, Masuda A, Nejima R, Maruyama Y, Miyata K. The antiinflammatory effect of $0.1 \%$ bromfenac and $0.1 \%$ betamethasone combination in post-cataract surgery patients with diabetes mellitus. Nippon Ganka Gakkai Zasshi. 2014;118(8):645-651.

71. Hoy SM. Bromfenac ophthalmic solution $0.07 \%$ : a review of its use after cataract surgery. Clin Drug Invest. 2015;35(8):525-529.

72. von Jagow B, Ohrloff C, Kohnen T. Macular thickness after uneventful cataract surgery determined by optical coherence tomography. Graefes Arch Clin Exp Ophthalmol. 2007;245(12):1765-1771.

73. Sahin M, Cingü AK, Gözüm N. Evaluation of cystoid macular edema using optical coherence tomography and fundus autofluorescence after uncomplicated phacoemulsification surgery. J Ophthalmol. 2013; 2013:376013.

74. Wittpenn JR, Silverstein S, Heier J, et al. A randomized, masked comparison of topical ketorolac $0.4 \%$ plus steroid vs steroid alone in low-risk cataract surgery patients. Am J Ophthalmol. 2008;146(4):554-560.

75. Rho DS, Tractenberg R, Soll SM, Markovitz BJ. Treatment of acute pseudophakic cystoid macular edema: bromfenac $0.09 \%$ versus diclofenac sodium $0.1 \%$ versus ketorolac tromethamine $0.5 \%$. In: Proceedings of the 112th Annual American Academy of Ophthalmology (AAO) Meeting, Atlanta, GA, November 11, 2008, A077.

76. Saviano BM, Crisci E, Viola G, Gentile R, Gentile S, Di Staso S. IrvineGass syndrome after cataract surgery resolved by topical therapy with bromfenac eyedrops. JCRS Online Case Rep. 2014;2:e1-e4.

77. Warren KA, Bahrani H, Fox JE. NSAIDs in combination therapy for the treatment of chronic pseudophakic cystoid macular edema. Retina. 2010;30(2):260-266.

78. Kadrmas EF. Bromfenac for the treatment of chronic pseudophakic cystoid macular edema. Invest Ophthalmol Vis Sci. 2009;50:1345.
Clinical Ophthalmology

\section{Publish your work in this journal}

Clinical Ophthalmology is an international, peer-reviewed journa covering all subspecialties within ophthalmology. Key topics include: Optometry; Visual science; Pharmacology and drug therapy in eye diseases; Basic Sciences; Primary and Secondary eye care; Patient Safety and Quality of Care Improvements. This journal is indexed on Submit your manuscript here: http://www.dovepress.com/clinical-ophthalmology-journa

\section{Dovepress}

PubMed Central and CAS, and is the official journal of The Society of Clinical Ophthalmology (SCO). The manuscript management system is completely online and includes a very quick and fair peer-review system, which is all easy to use. Visit http://www.dovepress.com/ testimonials.php to read real quotes from published authors. 